\title{
Macrophage Inhibitory Cytokine-1 Regulates Melanoma Vascular Development
}

\author{
Sung Jin Huh, ${ }^{*}$ Chin-Ying Chung, ${ }^{*}$ Arati Sharma, ${ }^{* \dagger}$ \\ and Gavin P. Robertson* ${ }^{\star \dagger \S}$ \\ From the Departments of Pharmacology,* Dermatology, ${ }^{\ddagger}$ and \\ Pathology, "Penn State Melanoma Therapeutic Program, ${ }^{\dagger}$ and \\ The Foreman Foundation for Melanoma Research, ${ }^{\S}$ The \\ Pennsylvania State University College of Medicine, Hershey, \\ Pennsylvania
}

Expression of macrophage inhibitory cytokine-1 (MIC-1), a member of the transforming growth factor- $\beta$ family, normally increases during inflammation or organ injury. MIC- 1 is also expressed at higher levels in melanomas; however, its role in tumorigenesis is unknown. This report identifies a novel function for MIC-1 in cancer. MIC-1 was overexpressed in $\sim 67 \%$ of advanced melanomas, accompanied by fivefold to six-fold higher levels of secreted protein in serum of melanoma patients compared with normal individuals. Constitutively active mutant ${ }^{\mathrm{V} 600 \mathrm{E}} \mathrm{B}$-Raf in melanoma regulated downstream MIC-1 expression. Indeed, small-interfering RNA-mediated targeting of MIC-1 or ${ }^{{ }^{600}}$ B-Raf reduced expression and secretion by three-fold to fivefold. This decrease in MIC-1 levels reduced melanoma tumorigenesis by approximately threefold, but did not alter cultured cell growth, suggesting a unique function other than growth control. Instead, inhibition of MIC-1 was found to mechanistically retard melanoma tumor vascular development, subsequently affecting tumor cell proliferation and apoptosis. This role in melanoma angiogenesis was confirmed by comparing MIC-1 and vascular endothelial growth factor (VEGF) function in chick chorioallantoic membrane and matrigel plug assays. Similar to VEGF in melanomas, MIC-1 stimulated directional vessel development, acting as a potent angiogenic factor. Thus, MIC-1 is secreted from melanoma cells together with VEGF to promote vascular development mediated by ${ }^{\mathrm{V} 600 \mathrm{E}}$ B-Raf signaling. (Am J Pathol 2010, 176:2948-2957; DOI: 10.2353/ajpath.2010.090963)

The transforming growth factor- $\beta$ (TGF- $\beta$ ) family of cytokines is a large multifunctional collection of proteins reg- ulating cellular proliferation, migration, cell adhesion, immune surveillance, and angiogenesis. ${ }^{1}$ TGF- $\beta$ family members function by relaying signals from serine/threonine kinase receptors in the cell membrane to activate signaling cascades controlling transcriptional activators and repressors. ${ }^{1,2}$ The role of TGF- $\beta$ family members in cancer is an active area of research with specific roles dependent on stage of tumor development and cancer type. ${ }^{1,2}$

One member of the TGF- $\beta$ family is the macrophage inhibitory cytokine-1 (MIC-1), which was originally identified as a factor overexpressed in activated macrophages to regulate inflammation. ${ }^{3}$ Under normal physiological conditions, placenta is the only tissue expressing large quantities of MIC-1. ${ }^{4}$ However, expression increases during inflammation or organ injury. ${ }^{4,5}$

A role for $\mathrm{MIC}-1$ in cancer is starting to emerge, but its functional significance in tumorigenesis is unknown. 6,7 Expression of MIC-1 increases in carcinomas of the breast, colon, pancreas, and prostate. ${ }^{4,7,8}$ Increased expression in cancer cells can be accompanied by elevated protein levels in the serum of patients. ${ }^{8-13}$ Secreted MIC-1 also has no identified role in cancer development.

The mitogen-activated protein (MAP) kinase pathway is deregulated in $\sim 60 \%$ of sporadic melanoma through mutation of $B$-Raf into a constitutively active V600E ( $\left.{ }^{\mathrm{V} 600 \mathrm{E}} \mathrm{B}-\mathrm{Raf}\right)$ form. ${ }^{14,15}$ This activated pathway in turn regulates diverse processes aiding tumor development such as proliferation, apoptosis, metastasis, and angiogenesis. ${ }^{16-19}$ MIC-1 has not been directly linked to the ${ }^{{ }^{600 E}} \mathrm{~B}-$ Raf pathway in melanomas.

MIC-1 has been reported as being overexpressed in melanomas compared with benign lesions. ${ }^{20-22}$ Furthermore, inhibition of MIC-1 using short hairpin RNA (shRNA) decreased melanoma tumor development, but the mechanism promoting tumorigenesis is unknown. ${ }^{22}$ This study reveals that MIC-1 can be regulated through

Supported by NIH grant CA-127892, American Cancer Society grant RSG-04-053-01-GMC, and The Foreman Foundation for Melanoma Research

Accepted for publication February 25, 2010

Address reprint requests to Gavin P. Robertson, Ph.D., The Pennsylvania State College of Medicine, Department of Pharmacology-R130, 500 University Dr. Hershey, PA 17033. E-mail: gprobertson@psu.edu. 
V600EB-Raf signaling and that it plays a novel role in melanoma development. MIC-1 is shown to be overexpressed in $\sim 67 \%$ of aggressive melanomas and accompanied by elevated protein levels in the serum of patients. Small-interfering RNA (siRNA)-mediated targeting of MIC-1 reduced expression and secretion thereby retarding vascular development, which decreased the tumorigenic potential of melanoma cells by $60 \%$ to $70 \%$.

\section{Materials and Methods}

\section{Cell Lines and Culture Conditions}

Melanoma cell lines, UACC 903, C8161, and A375M, were maintained in Dulbecco's modified Eagle's medium (Invitrogen, Carlsbad, CA) supplemented with 10\% fetal bovine serum (Hyclone, Logan, UT). Melanocytes and melanoma cell lines WM35, WM3211, WM 98.1, WM115, and WM278 were maintained as described previously. ${ }^{23}$

\section{SiRNA Targeting MIC-1}

SiRNA (100 pmol) was introduced into $1.0 \times 10^{6}$ UACC 903 or A375M via nucleofection by using an Amaxa Nucleofector (Koeln, Germany) using Solution R/program K-17 or A-23, respectively. ${ }^{16-18,23,24}$ Transfection efficiency was $>95 \%$ with $80 \%$ to $90 \%$ cell viability. ${ }^{17,23}$ After siRNA introduction into cells, cells were allowed to recover for 2 days and then replated in 96-well plates. Five days later, cell viability was measured by using the 3-(4,5-dimethylthiazol-2-yl)-5-(3-carboxymethoxyphenyl)-2-(4-sulfophenyl)-2H-tetrazolium, inner salt (MTS) assay (CellTiter 96 AQueous Cell Proliferation Assay; Promega, Madison, WI). Duplexed Stealth siRNA (Invitrogen) were used for these studies. The following siRNA sequences were used: ${ }^{V 600 E} B$-Raf: 5'-GGUCUAGCUACAGAGAAAUCUCGAU-3'; MIC-1\#1: 5'-GAUUCCGAGAGUUGCGGAAACGCUA-3'; MIC-1\#2: 5'-CAAGAACUCAGGACGGUGAAUGGCU-3'; MIC-1\#3: 5'-UCGGACCAACUGCUGGCAGAAUCUU-3'; and vascular endothelial growth factor (VEGF): 5'-GCACATAGGAGAGATGAGCTTCCTA-3'.

\section{Ectopic Expression of ${ }^{{ }^{600}}{ }^{B}$-Raf Constructs}

Five, 7.5 , and $10 \mu \mathrm{g}$ of hemagglutinin-tagged ${ }^{{ }^{600 E}}{ }^{B-R a f}$ constructs $^{25}$ were introduced into C8161 cells with the Amaxa Nucleofector by using the K17 program. Transfection efficiencies were determined to be $\sim 70 \%$ by using pMaxGFP (Koeln, Germany) as a green fluorescent protein expression plasmid control.

\section{MIC-1 and VEGF Sandwich Enzyme-Linked Immunosorbent Assay}

MIC-1 sandwich enzyme-linked immunosorbent assay (ELISA) was used for quantification of protein levels in cell culture media and blood samples with the DuoSet ELISA for human GDF15 (R\&D Systems, Minneapolis, $\mathrm{MN}$ ) following the manufacturer's protocol. After introduc- ing siRNA by nucleofection, cells were replated and media were changed 24 hours later into fresh Dulbecco's modified Eagle's medium (Invitrogen) supplemented with $10 \%$ fetal bovine serum (Hyclone). The next day, conditioned media were collected from the plates and analyzed. Assays were replicated at least twice. For VEGF, the human VEGF Quantikine kit (DVE00; R\&D Systems) was used according to the manufacturer's instructions.

\section{Western Blot Analysis}

Western blot analysis was undertaken as described previously. ${ }^{23,25,26}$ Blots were probed with antibodies according to each supplier's recommendations: antibodies to MIC-1 (NAG-1) from Upstate Inc. (Lake Placid, NY) and B-Raf, $\alpha$-enolase, from Santa Cruz Biotechnology (Santa Cruz, CA). Secondary antibodies conjugated with horseradish peroxidase were obtained from Santa Cruz Biotechnology. Immunoblots were developed by using the enhanced chemiluminescence detection system (Amersham Pharmacia Biotech, Piscataway, NJ). Blots were normalized to $\alpha$-enolase and quantified by using ImageJ software. ${ }^{27,28}$ Analyses were replicated at least twice.

\section{Animal Studies}

All animal experiments were done according to protocols approved by the Institutional Animal Care and Use Committee at The Pennsylvania State University. Tumor formation was measured in athymic-Foxn $1^{\text {nu }}$ nude mice purchased from Herlan Sprague Dawley (Indianapolis, IN). Five hundred picomoles of siRNA was nucleofected into $5.0 \times 10^{6}$ cells and after 48 hours of recovery, $1.0 \times 10^{6}$ cells were collected in $0.2 \mathrm{ml}$ of $10 \%$ fetal bovine serumDulbecco's modified Eagle's medium to inject subcutaneously above both the left and right rib cages of 4- to 6-week-old female mice. Each group contained five mice, and each experiment was replicated twice. Dimensions of developing tumors were measured on alternate days by using calipers. Assays were replicated at least twice.

\section{Studies Involving Human Melanoma Patient Tumors}

All experiments using human material were undertaken according to protocols approved by the Institutional Review Board Committee at The Pennsylvania State University. Tissue samples were collected from 29 patients at surgery, immediately snap frozen in liquid nitrogen, and stored at $-80^{\circ} \mathrm{C}$ until protein lysate collection. To collect protein for Western blotting, tumors were pulverized by using a mortar and pestle chilled in liquid nitrogen. Protein lysates were extracted from tumors as reported previously $^{23}$ and analyzed by Western blotting to measure levels of MIC-1. MIC-1 protein levels in tumors were normalized to an $\alpha$-enolase loading control to quantify the relative quantity of $\mathrm{MIC}-1$ expression by using ImageJ software. Fresh blood was collected from donors who were approved by the Biomedical Institutional Review 
Board at The Pennsylvania State University (HYO2101EP-A), with informed consent provided according to the Declaration of Helsinki. For ELISA analysis, serum samples were obtained after removal of blood cells and stored at $-80^{\circ} \mathrm{C}$ until analysis. Analyses were replicated at least twice.

\section{Cell Proliferation, Apoptosis, and Vessel Density Analysis in Time-Size Matched Tumors}

To generate tumors of the same size developing at parallel time points, $1.0 \times 10^{6}$ cells were injected into nude mice for UACC 903 cells nucleofected with either water control or scrambled siRNA and $2.0 \times 10^{6}$ cells injected for UACC 903 cells nucleofected with MIC-1 siRNA. Time and size matched tumors were harvested 9, 11, and 13 days later to assess changes in cell proliferation, apoptosis, and vessel density. Cell proliferation rates in formalinfixed tumor sections were measured by using Ki-67 staining as described previously. ${ }^{16,26}$ The number of Ki-67stained cells was quantified as the percentage of total cells in tumors. Apoptosis rates were measured on formalin-fixed, paraffin-embedded tumor sections by using the terminal deoxynucleotidyl transferase-mediated dUTP nick-end labeling tetramethylrhodamine (TMR) red apoptosis kit from Roche (Mannheim, Germany). ${ }^{16,26}$ Analyses were replicated at least twice.

\section{Chick Chorioallantoic Membrane Assay}

Day 0 fertilized White Leghorn eggs were provided by Hy-Line North America (Elizabethtown, PA) and used for the chorioallantoic membrane (CAM) assay according to published procedures. ${ }^{29}$ Eggshells were cleaned with $70 \%$ ethanol and turned parallel in an incubator rack maintained at $37^{\circ} \mathrm{C}$ with $60 \%$ to $70 \%$ humidity. To prevent CAM adhesion to the inner eggshell, eggs were rotated frequently until albumen removal. Two milliliters of albumen was removed from the pointed end of each egg by using a $21 \mathrm{G}$ syringe-needle on day 3. A second hole was made to puncture the air sac on the other end of the egg, causing the CAM to pull away from the shell membrane. A $1.0 \times 1.0 \mathrm{~cm}$ square window was cut through the shell over the area from which the CAM had retracted with the use of a diamond-tipped glass slide marker. The window was sealed with transparent tape, and embryos were incubated to enable development of a full vasculature. On day 10, $1.0 \mathrm{~mm}^{2}$ filter papers impregnated with varying concentrations of recombinant MIC-1 or media from cells nucleofected with siRNA were implanted on top of the CAM. Capillary tube formation was examined 3 days later, when the angiogenic response had peaked. CAM was fixed by injecting $2 \mathrm{ml}$ ice-cold $4 \%$ paraformaldehyde-PBS into the egg and on top of the CAM that was left at $4^{\circ} \mathrm{C}$ overnight. The next day, the CAM was excised with small dissection scissors and forceps. It was placed in PBS and mounted on a microscope slide. Blood vessels entering the paper were photographed and counted. Assays were replicated at least twice.

\section{Matrigel Plug Assay}

Recombinant VEGF (200 pg/ml, VEGF165, R\&D Systems) or MIC-1 (2.5 ng/ml or $5.0 \mathrm{ng} / \mathrm{ml}$, GDF-15, R\&D Systems) either alone or in combination was mixed with unpolymerized liquid Matrigel (BD Biosciences, San Jose, CA) containing $20 \mu \mathrm{g} / \mathrm{ml}$ heparin at $4^{\circ} \mathrm{C}$. Matrigel $(0.6 \mathrm{ml}$ each) was injected subcutaneously into the abdominal region of C57/BL6 female mice by using a cold syringe. At body temperature, the Matrigel polymerized to form a solid gel plug. Each group contained four mice with two plugs per mice. After 10 days, gels from all groups were collected and fixed overnight in fresh 10\% formalin and then paraffin embedded for H\&E staining. Blood vessels in Matrigel plugs were quantified by using microscopy to score the area occupied by vessels over total area calculated by using the IP Lab imaging software program (San Jose, CA). Assays were replicated at least twice.

\section{Statistical Analysis}

One-way analysis of variance or nonparametric one-way analysis of variance Kruskal-Wallis test followed by Dunnett's or Bonferroni multiple comparison tests were used to establish statistical significance. Results were considered significant at a $P$ value of $<0.05$.

\section{Results}

\section{MIC-1 Protein Expression and Secretion Are Elevated in Melanoma Patients}

Although MIC-1 is known to be overexpressed in melanomas, it is unknown whether it is secreted into the serum of melanoma patients. ${ }^{22}$ Figure $1 \mathrm{~A}$ shows that $66.7 \%$ (18 of 27) of melanoma patients have advanced metastatic tumors that express MIC-1 protein at higher levels than that observed in normal human melanocytes, confirming prior reports. To extend this prior knowledge, serum from 10 metastatic melanoma patients was examined and found to have MIC-1 levels ranging from 0.5 to $3.2 \mathrm{ng} / \mathrm{ml}$ compared with healthy blood donors having concentrations ranging from 0.2 to $0.4 \mathrm{ng} / \mathrm{ml}$. Patients who had elevated expression of MIC-1 in tumors also had high levels of MIC-1 in their blood serum (Figure 1, A and B, labeled a, b, and c). Eighty percent of patients had serum MIC-1 levels higher than $1 \mathrm{ng} / \mathrm{ml}$ (Figure 1B). Thus, metastatic melanoma patients having elevated MIC-1 expression in tumors also had high levels of MIC- 1 in blood serum.

\section{MIC-1 Protein Is Not Expressed in Normal Skin Cells but Is Overexpressed in Melanoma Cell Lines}

Levels of MIC-1 protein were measured in a variety of melanoma cell lines derived from primary tumors at the radial (RGP; WM35 and WM3211), vertical (VGP; WM115, WM98.1, and WM278) and metastatic (MM; UACC 903) 
A MIC-1 levels in melanoma patient tumor samples

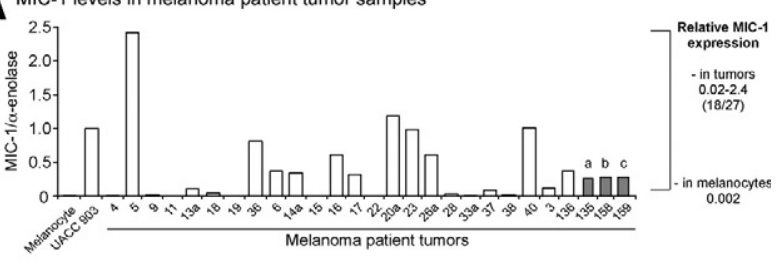

B MIC-1 levels in melanoma patient serum samples
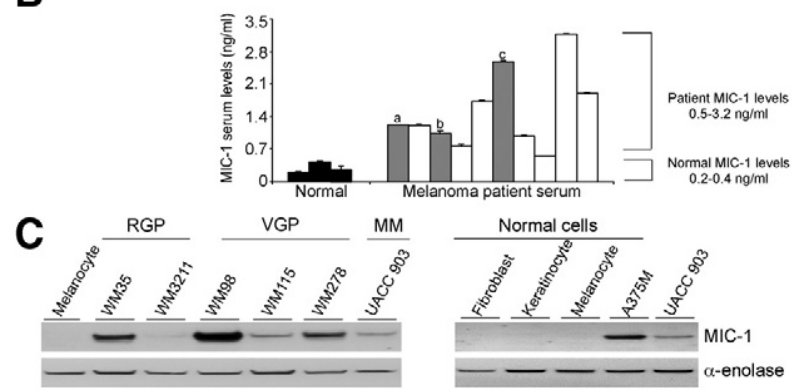

D

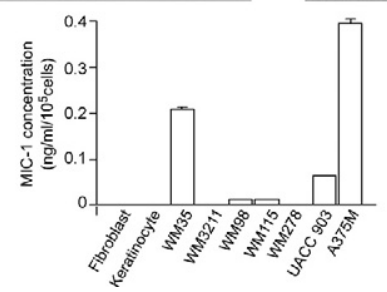

Figure 1. MIC-1 is overexpressed in and secreted from melanomas. A: MIC-1 protein was expressed at higher levels in melanoma patient tumors compared with normal human melanocytes. $\alpha$-Enolase served as a control for equal protein loading. B: MIC-1 concentrations are elevated in the blood serum of melanoma patients compared with normal individuals. MIC-1 concentrations in blood serum of melanoma patients were measured by ELISA. Values are presented as mean \pm SEM. C: MIC-1 is overexpressed in the majority of melanoma cell lines. Expression of MIC-1 was examined in melanoma cell lines established from primary tumors at the radial (RGP; WM35 and WM3211), vertical (VGP; WM115, WM98.1, and WM278), and metastatic (MM; UACC 903) stages of melanoma progression. Only WM3211 did not express MIC-1 at levels higher than that observed in melanocytes. Normal skin melanocytes, fibroblasts, and keratinocytes did not contain detectable levels of MIC-1 protein by Western blotting. $\alpha$-Enolase was used as a control for equal protein loading. D: MIC-1 was secreted from metastatic melanoma cell lines but not at significant levels from RGP or VGP cell lines. MIC-1 concentrations in media were measured by ELISA. Values are presented as mean \pm SEM.

stages of melanoma progression and compared with normal skin cells. All melanoma cell lines, except for WM3211 cells, expressed MIC-1 levels higher than occurs in normal human melanocytes (Figure 1C). Furthermore, MIC-1 expression and secretion was also not detectable in normal human fibroblasts or keratinocytes found in skin (Figure 1, C and D). Barely detectable levels of MIC-1 were found in conditioned media collected from RGP (except WM35) and VGP cell lines; however, high levels were observed in metastatic UACC 903 and A375M melanoma cell lines (Figure 1D). WM35 seems to be an aberration among the group because the majority of RGP and VGP cells lines express but do not secrete the protein at high levels. In contrast, both metastatic melanoma cell lines and serum from metastatic melanoma patients express and secrete significant levels of MIC-1 (Figure 1). Thus, MIC-1 is overexpressed in and secreted from metastatic melanomas, but although present in the majority of RGP or VGP cells lines, it is generally not secreted to very high levels from them.

\section{Targeting ${ }^{{ }^{6} 60 E_{B}} B$-Raf in the MAP Kinase-Signaling Cascade Decreased MIC-1 Expression}

It is unknown as to which aberrant pathways promote MIC-1 deregulation in melanomas. Therefore, to test whether it might be regulated by ${ }^{\mathrm{V} 600}{ }_{B} \mathrm{~B}-$ Raf signaling, siRNA was used to decrease ${ }^{{ }^{6}{ }^{6} E_{B}-R a f}$ protein levels and effect on MIC-1 expression examined. SiRNA targeting ${ }^{\mathrm{V} 600 \mathrm{E}_{\mathrm{B}}-\mathrm{Raf} \text { or }}$ three different regions of MIC-1 were introduced into UACC 903 or A375M via nucleofection, and Western blotting was used to show significant reduction of each respective protein (Figure 2, A and B). In UACC 903 cells, all three siRNAs targeting MIC-1 similarly inhibited protein expression by $>80 \%$ compared with control cells nucleofected with buffer or scrambled siRNA (Figure 2A). However, in A375M melanoma cells, only siMIC-1 number 1 and siMIC-1 number 3 reduced MIC-1 protein expression by $\sim 80 \%$ (Figure $2 \mathrm{~B}$ ). The latter results were not unusual because normal sequence variation can affect the efficacy of siRNA in certain but not other cell lines. ${ }^{28,30}$ Importantly, decreased ${ }^{\text {V600E }}$ BRaf protein levels in both cell lines reduced expression of MIC-1, suggesting that it lies downstream in the MAP kinase pathway. In contrast, targeting MIC-1 by using siRNA did not alter B-Raf protein expression (Figure 2, A and B). Thus, MIC-1 expression in melanomas appears to be mechanistically regulated through ${ }^{\mathrm{V} 600 \mathrm{E}} \mathrm{B}$-Raf signaling.

\section{Targeting MIC-1 or Upstream ${ }^{{ }^{600}}$ B-Raf Decreased Secretion from Melanoma Cells}

Next, siRNA was introduced into melanoma cells and effect on secreted MIC-1 was measured (Figure 2, C and D). ELISA showed that siRNA-mediated targeting of MIC-1 reduced secreted levels by 3.5 -fold from 3 to 0.8 $\mathrm{ng} / \mathrm{ml}$ for UACC 903 cells (Figure 2C) and by eightfold from 17 to $2 \mathrm{ng} / \mathrm{ml}$ for A375M cells (Figure 2D). SiRNAmediated targeting of ${ }^{V} 600 E_{B}$-Raf similarly reduced secreted MIC-1 concentrations (Figure 2, C and D). Thus,

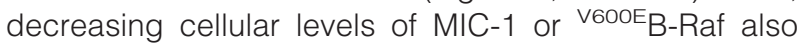
reduced $\mathrm{MIC}-1$ levels secreted into culture media.

\section{Decreasing MIC-1 Protein Levels in Melanoma Cells Does Not Alter Growth in Culture}

Because MIC-1 was found to lie downstream of ${ }^{{ }^{6} 600 E_{B}}$ Raf signaling, which is known to regulate cellular proliferation, effects on cell growth were examined after

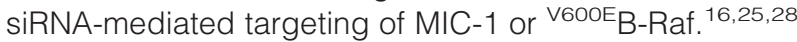

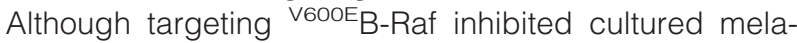
noma cell growth by $\sim 80 \%$ (Figure $3 \mathrm{~A}$ ), reducing $\mathrm{MIC}-1$ protein levels had no effect on UACC 903 or A375M cell growth compared with controls, suggesting a function other than growth control (Figure 3A). Thus, even though MIC-1 lies downstream of ${ }^{{ }^{6} 600} \mathrm{~B}$-Raf, it does not regulate melanoma cells growth. 


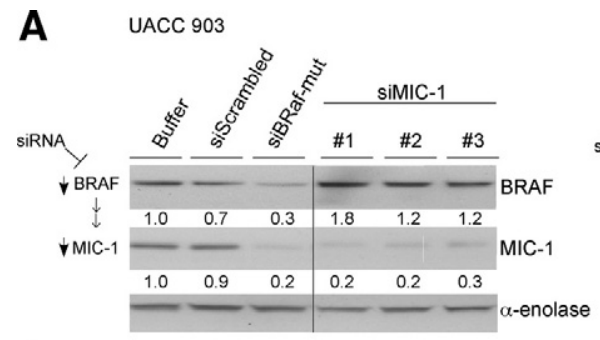

C MIC-1 secretion in UACC 903 media

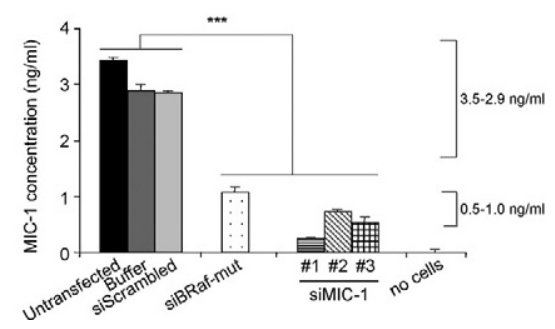

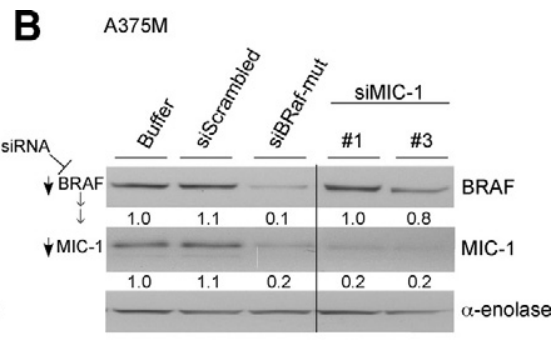

D MIC-1 secretion in A375M media

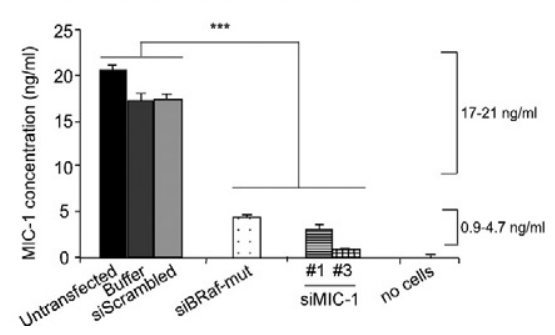

Figure 2. Targeting mutant ${ }^{{ }^{6 O O E}} B$-Raf reduced levels of MIC-1 protein expression in and secretion from melanoma cells. SiRNA-mediated inhibition of mutant ${ }^{V G O O E} B-R a f$ significantly reduced MIC-1 protein expression in UACC 903 (A) and A375M (B) melanoma cells compared with untransfected controls or cells nucleofected with buffer or scrambled siRNA. Reduction of mutant ${ }^{\mathrm{V} 600 \mathrm{E}} \mathrm{B}$-Raf protein expression decreased MIC-1 levels similar to that observed after inhibition of MIC-1 expression by using siRNA. $\alpha$-Enolase was used as a control for equal protein loading. Inhibition of mutant ${ }^{V 6 O O E} B$-Raf reduced MIC-1 secretion from UACC 903 (C) and A375M (D) melanoma cells. Media alone were used as a negative control. Values are presented as mean \pm SEM. ${ }^{* * * *} P<0.001$ compared with controls.

\section{Ectopic Expression of ${ }^{\mathrm{V} 600 E}$ B-Raf in Melanoma Cells Containing Wild-Type B-Raf Increased} MIC-1 Secretion

To confirm that constitutively active ${ }^{{ }^{6} 60 E_{B}}$-Raf protein regulates $\mathrm{MIC}-1$ expression and secretion, HA-tagged ${ }^{\text {V600E }}$ B-Raf was transiently transfected into C8161 melanoma cells lacking the mutation and having low pathway

\section{A In vitro Cell Growth}
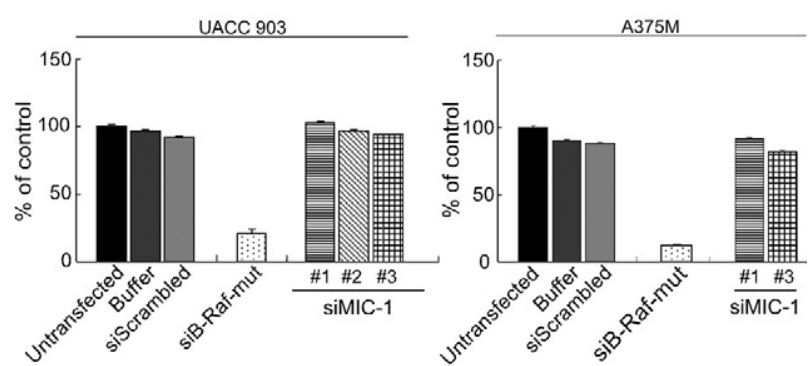

B C8161
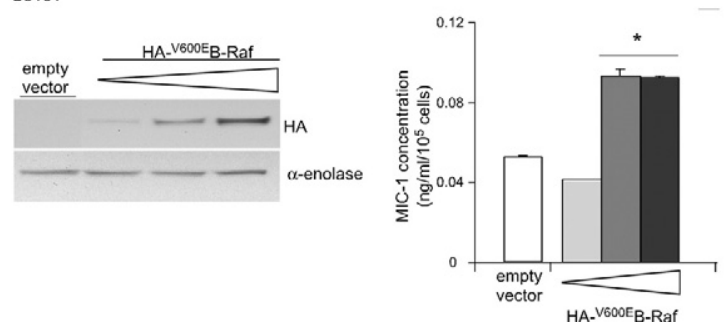

Figure 3. Decreasing MIC-1 expression does not alter the growth of cultured melanoma cells. A: SiRNA-mediated knockdown of MIC-1 protein expression did not affect the growth of cultured melanoma cells. UACC 903 or A375M cell viability was measured by using an MTS assay after siRNA-mediated knockdown of MIC-1. Values are presented as mean \pm SEM. ${ }^{\mathrm{V} 600 \mathrm{E}} \mathrm{B}-\mathrm{Raf}$ protein knockdown was used as a positive control for inhibition of cell growth. B: Ectopic expression of HA-tagged- ${ }^{\mathrm{V} 600 \mathrm{E}} \mathrm{B}$-Raf led to a $50 \%$ increase in secretion of MIC-1 from melanoma cells. HA-tagged- ${ }^{\mathrm{V} 600 \mathrm{E}} \mathrm{B}-\mathrm{Raf}(5.0,7.5$, and $10 \mu \mathrm{g}$ of construct) was ectopically expressed in C8161 melanoma cells lacking ${ }^{\mathrm{V} 600 \mathrm{E}} \mathrm{B}$-Raf. Western blotting shows expression of HA-tagged protein. $\alpha$-Enolase was used as a control for equal protein loading. ELISA showed a $50 \%$ increase in MIC-1 secretion from cells expressing HA-tagged- ${ }^{\mathrm{V} 600 \mathrm{E}} \mathrm{B}-\mathrm{Raf}$ compared with controls. Values are presented as mean \pm SEM. ${ }^{*} P<0.05$ compared with controls. activity. Cells ectopically expressing HA- ${ }^{\text {6600E }}$ B-Raf had $\sim 50 \%$ higher levels of secreted MIC-1, compared with vector-transfected control cells (Figure $3 \mathrm{~B}$, ${ }^{*} P<0.05$, one-way analysis of variance). Thus, MIC-1 secretion can be regulated by ${ }^{{ }^{600 E}} \mathrm{~B}$-Raf signaling in melanomas.

\section{Decreased MIC-1 Protein Expression Stunts Melanoma Tumor Development}

To identify the functional role played by MIC-1 in melanoma development, an established published approach was used in which siRNA was introduced into UACC 903 and $A 375 \mathrm{M}$ and subsequently injected in nude mice. ${ }^{16,26}$ Developing tumor sizes were measured on alternate days up to 19.5 days. SiRNA-mediated targeting of MIC-1 in both UACC 903 (Figure 4A) and A375M (Figure 4B) melanoma cells reduced tumorigenesis by $60 \%$ to $70 \%$. Tumors initially grew to $\sim 100 \mathrm{~mm}^{3}$ for UACC 903 and $\sim 50 \mathrm{~mm}^{3}$ for $\mathrm{A} 375 \mathrm{M}$ cells followed by a prolonged period of no or minimal growth. Serum collected from control mice containing A375M xenografted tumors at day 19.5 was analyzed for MIC-1 levels by ELISA and showed the presence of $50 \%$ to $75 \%$ less secreted protein in tumors in which $\mathrm{MIC}-1$ expression had been reduced by using siRNA compared with controls (Figure 4C). Thus, throughout this experiment, MIC-1 levels in blood serum remained low compared with controls mediated by the siRNA introduced into the cells.

\section{Targeting MIC-1 Retards Melanoma Vascular Development}

To identify the underlying mechanism by which MIC-1 inhibition impedes melanoma tumor development, an established published approach was used. ${ }^{16,26}$ It involves quantifying the rates of tumor angiogenesis (using CD31 stating), cell proliferation (using Ki-67), and apoptosis (using terminal deoxynucleotidyl transferase-mediated dUTP nick-end labeling) in time and size matched tumors 


\section{A UACC 903 tumor development}

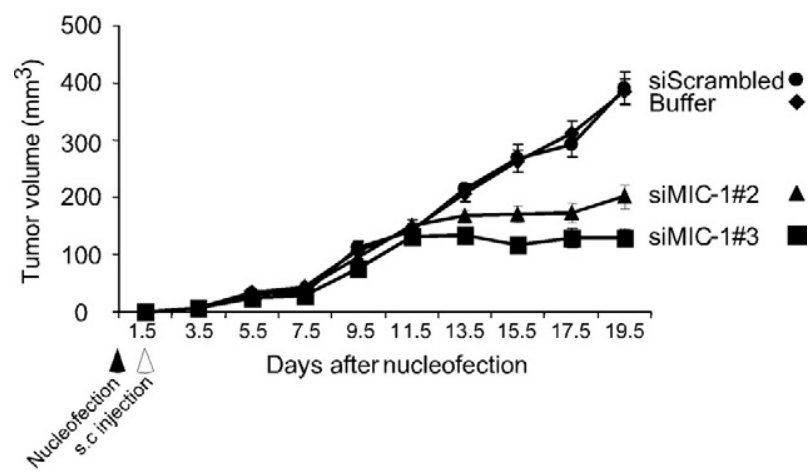

B A375M tumor development

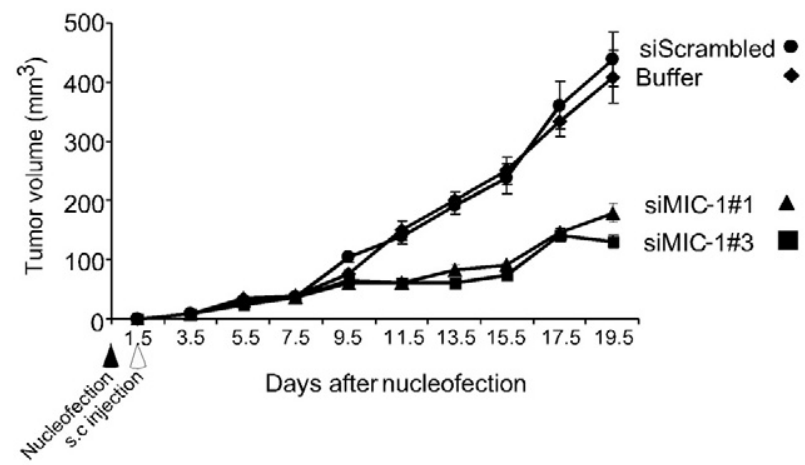

C Serum levels of MIC-1 from mice containing xenografted tumors at day 19.5

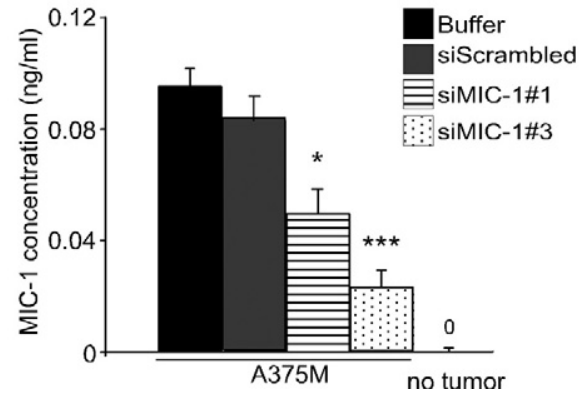

Figure 4. SiRNA-mediated inhibition of MIC-1 retarded the tumorigenic potential of melanoma cells. Targeting MIC-1 by using siRNA inhibits melanoma tumor development. SiRNA targeting MIC-1, siScrambled, or buffer controls were nucleofected into UACC 903 (A) or A375M (B) cell lines, and 36 hours later, cells were subcutaneously injected into nude mice. Tumor size was measured on alternate days up to day 19.5. Values are presented as mean \pm SEM. C: siRNA-mediated inhibition reduced MIC-1 levels in mouse blood serum by $50 \%$. At day 19.5 after nucleofection of siRNA targeting MIC-1, levels secreted from A375M tumors were measured from five separate mice by ELISA. Mice lacking xenografted tumors were used as negative control. Values are presented as mean \pm SEM. ${ }^{*} P<0.05$; ${ }^{* * * *} P<0.001$ compared with controls.

treated with siRNA targeting MIC-1 compared with controls. Cells were subcutaneously injected into nude mice, and on days 9, 11, and 13, size-matched tumors were removed from animals. Decreased $\mathrm{MIC}-1$ protein expression of $50 \%$ was observed from day 13 for UACC 903 and A375M xenografted tumors, which were normalized against $\alpha$-enolase (Figure 5A). Blood serum collected at day 13 from mice containing tumors in which MIC-1 expression has been reduced by using siRNA showed a statistically significant $50 \%$ decrease compared with controls (Figure 5B, ${ }^{\star} P<0.05$, ${ }^{\star \star} P<0.01$ one-way analysis of variance). Size and time matched tumors at each time were then compared with the first statistically quantifiable difference in vascular development, proliferation, or apoptosis to identify the key event through which MIC-1 regulated tumorigenesis. ${ }^{16,26}$ At day 9, a statistically significant $50 \%$ reduction in vessel development was observed after MIC-1 targeting but not in cellular proliferation or apoptosis rates compared with buffer or scrambled siRNA controls (Figure $5 \mathrm{C}$, ${ }^{\star} P<0.05$, ${ }^{\star \star} P<$ 0.01 , one-way analysis of variance). There was a significant difference in proliferation between control cells and those nucleofected with siMIC-1 number 3 at day 9; however, because this difference was not observed with siMIC-1 number 2, it was considered as an inconsistency and not the major cause of tumor inhibition. Similar significant differences in vascular development, cellular proliferation, and apoptosis were detected in all tumors compared with controls at days 11 and 13, suggesting that lack of development of an effective vascular network subsequently decreased cell proliferation and triggered apoptosis (Figure $5 \mathrm{C},{ }^{* *} P<0.01$, one-way analysis of variance). Thus, inhibiting $\mathrm{MIC}-1$ secretion by tumor cells retarded tumor angiogenesis, subsequently decreasing cellular proliferation and increasing apoptosis.

\section{Directional Vessel Growth Occurs Toward MIC- 1 in the Chick Chorioallantoic Membrane Vessel Stimulation Assay}

One technique to demonstrate that a secreted protein functions as an angiogenic factor measures vessel development in the direction of the protein by using the chick chorioallantoic membrane vessel stimulation assay. ${ }^{29}$ Filter papers $\left(1 \mathrm{~mm}^{2}\right)$ were soaked with physiological concentrations of recombinant $\mathrm{MIC}-1$ ranging from 2.5 to $500 \mathrm{ng} / \mathrm{ml}$ and placed on developing chick chorioallantoic membranes. The number of blood vessels growing toward recombinant MIC-1 in the filter paper was photographed and quantified 3 days later (Figure 6A). Compared with filter paper soaked with PBS, recombinant MIC-1 caused 100\% vessel growth toward the filter paper and also led to a twofold increase in vessel number from 2.5 to $10 \mathrm{ng} / \mathrm{ml}$, which plateaued at concentrations $>10 \mathrm{ng} / \mathrm{ml}$ (Figure 6A). Thus, secreted MIC-1 stimulated directional vessel development, demonstrating it can act as an angiogenic factor.

\section{Co-Stimulation of VEGF and MIC-1 Promotes Blood Vessel Formation}

Because VEGF secretion is also regulated by ${ }^{{ }^{6} 600 E_{B}-R a f}$ in malignant melanomas, ${ }^{16} \mathrm{MIC}-1$ and/or VEGF were targeted by using siRNA to reduce secretion of each respective protein to compare the role of each in melanoma (Figure $6 \mathrm{~B})$. Filter papers $\left(1 \mathrm{~mm}^{2}\right)$ soaked with conditioned media collected from cells nucleofected with siRNA targeting MIC-1 and/or VEGF were placed on de- 
A MIC-1 protein expression in time and size matched day 13 tumors $\quad \begin{aligned} & \text { Serum levels of MIC-1 from mice containing } \\ & \text { time and size matched day } 13 \text { tumors }\end{aligned}$
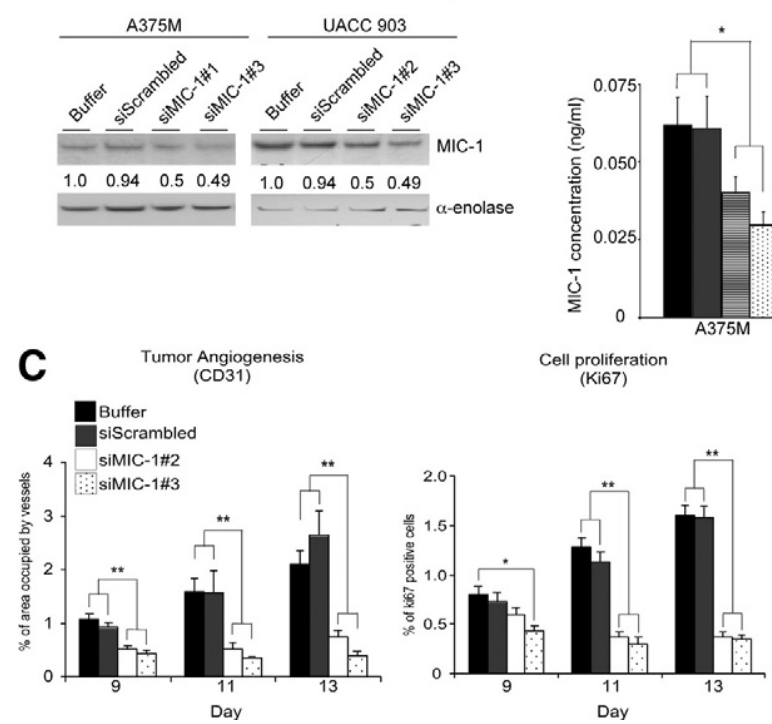

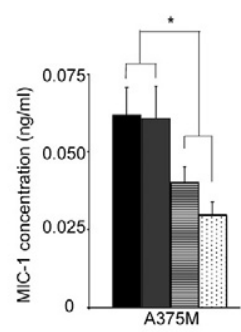

Cell proliferation

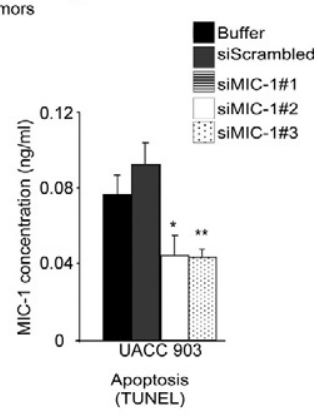

veloping chick chorioallantoic membranes. The number of blood vessels growing toward the proteins was photographed and quantified 3 days later (Figure 6B). Compared with control filter paper soaked with conditioned media from buffer and scrambled siRNA controls, conditioned media from cells having decreased MIC-1 or

Figure 5. Targeting MIC-1 reduced the angiogenic potential of melanoma cells to decrease melanoma tumor development. A: SiRNA-mediated inhibition of MIC-1 in A375M or UACC 903 tumors reduced protein expression by $50 \%$ in time and size matched tumors. B: siRNA-mediated inhibition of MIC-1 in A375M or UACC 903 tumors reduced serum levels of the protein in mice bearing day 13 time and sized matched tumors by $50 \%\left({ }^{*} P<0.05 ;{ }^{* *} P<0.01\right.$ compared with controls). C: SiRNA-mediated inhibition of MIC-1 reduced vascular development to decrease tumor development. Comparison of vascular development, proliferation, and cellular apoptosis rates in size and time matched UACC 903 tumors differing in MIC- 1 protein expression. Change in vascular development was the first statistically significant difference ( ${ }^{* *} P<$ 0.01 ) observed in size and time matched tumors in which MIC-1 was targeted by using siRNA. Reduced cell proliferation $\left({ }^{*} P<0.05\right.$; ${ }^{* * *} P<$ $0.01)$ and increased apoptosis (** $P<0.01)$ were consistently observed starting at day 11 . Columns represent means of 12 fields analyzed from four tumors per group; bars represent \pm SEM.
A
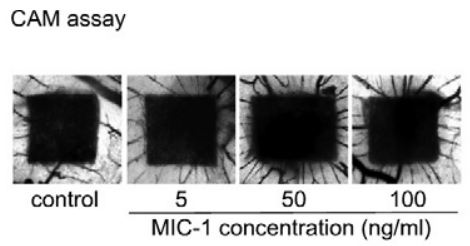

Quantification of vessel number

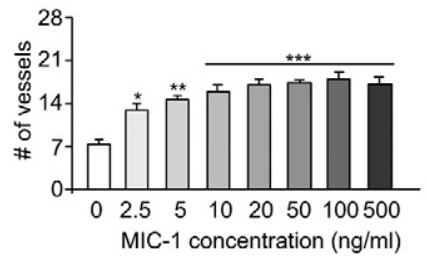

B

MIC-1 secretion

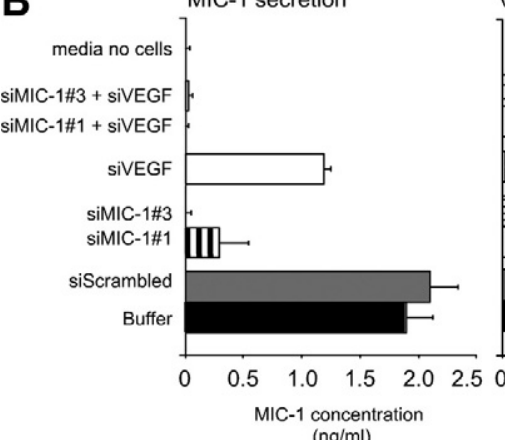

( $\mathrm{ng} / \mathrm{ml}$ )

C Matrigel plug assay (40x)

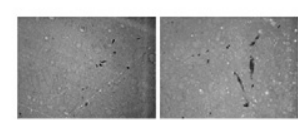

Control
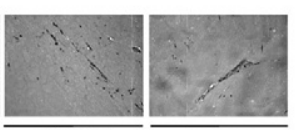

VEGF

$\stackrel{+}{\mathrm{MIC}-1}$

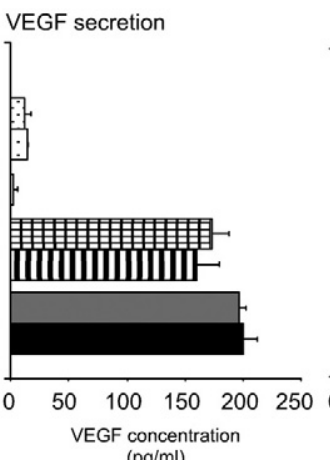

$(\mathrm{pg} / \mathrm{ml})$
VEGF secretion reduced vessel number by $40 \%$ (Figure $6 \mathrm{~B}$ ). Reducing levels of secreted MIC-1 and VEGF cooperatively reduced vessel to levels observed with media that had not been exposed to the cells. Thus, melanoma cells secrete MIC-1 to promote directional blood vessel development in a manner similar to VEGF.
CAM assay
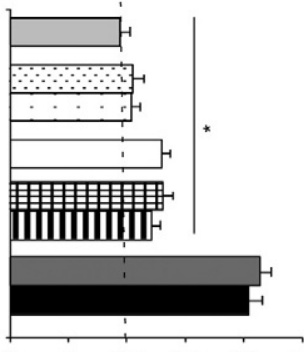

$\begin{array}{lllll}5 & 10 & 15 & 20 & 25\end{array}$

\# of vessels

Quantification of vessel number

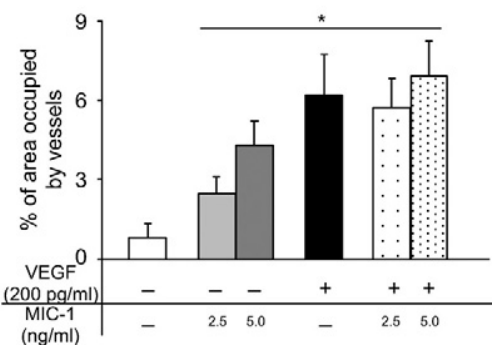

Figure 6. MIC-1 and VEGF promote melanoma vascular development. A: MIC-1 increased blood vessels formation in the direction of filter paper soaked with MIC-1. Quantification of newly formed blood vessels showed MIC-1 promoted angiogenesis in the CAM assay. A minimum of 20 filter papers were photographed (original magnification, $\times 40)$ and quantified to determine blood vessel number. PBS served as negative control. Values are presented as mean \pm SEM ${ }^{*} P<0.05 ;{ }^{* * *} P<0.01 ;{ }^{* * * * *} P<0.001$. B: Targeting MIC-1 and/or VEGF suppressed blood vessel formation compared with controls in the chick chorioallantoic membrane assay. SiRNA was used to decrease secreted levels of MIC-1 and/or VEGF and conditioned media used on a CAM assay. Values are presented as mean \pm SEM. C: MIC- 1 and VEGF stimulation alone and in combination increased formation of blood vessels in the matrigel plug assay. Matrigel was mixed with 2.5 or 5.0 $\mathrm{ng} / \mathrm{ml}$ of MIC-1 and/or $200 \mathrm{pg} / \mathrm{ml} \mathrm{VEGF}$ and injected subcutaneously into mice. After 10 days, matrigel plugs were removed, fixed, and photographed (original magnification, $\times 40$ ). Blood vessels formed in the gels were quantified. Values are presented as mean \pm SEM. ${ }^{*} P<0.05$ compared with controls. 
To further validate the angiogenic potential of MIC-1, an in vivo Matrigel plug assay was performed in which matrigel containing MIC-1 (2.5 ng/ml or $5.0 \mathrm{ng} / \mathrm{ml})$, VEGF $(200 \mathrm{pg} / \mathrm{ml})$, or a combination of both were injected subcutaneously in C57/BL6 mice. After 10 days, subcutaneous gel plugs were removed from mice and blood vessel development was quantified as the percentage of area occupied by vessels (Figure 6C). MIC-1 treatment led to a threefold to sixfold increase in blood vessel area compared with controls (Figure 6C). MIC-1 and VEGF together produced a 7.5 -fold increase in vessel development, which was greater that MIC-1 alone but not more than VEGF alone, suggesting the response had been maximized (Figure 6C). Thus, MIC-1 alone was sufficient to induce blood vessel formation, which could be enhanced in combination with VEGF.

\section{Discussion}

Fibroblast, keratinocytes, and melanocytes which are cells constituting the normal skin layer have undetectable levels of MIC-1, whereas $\sim 67 \%$ of melanoma patient tumors had measurable concentrations. This study shows that MIC-1 secreted from tumors can regulate an important process in melanoma development. Factors secreted by tumors are known to alter the surrounding environment by regulating immune, fibroblasts, or endothelial cells' activities to promote tumor development. ${ }^{31,32}$ Decreasing MIC-1 expression and secretion from melanoma cells did not alter cultured cell survival but significantly decreased tumor development, suggesting it could be regulating an extracellular process important in tumor development. Decreased tumor vascular development was observed in time and size matched tumors in which siRNA had been used to reduce MIC-1 protein expression compared with control tumors. Involvement of MIC-1 in melanoma angiogenesis was subsequently confirmed by showing that it could regulate angiogenesis in chick chorioallantoic membrane vessel stimulation and matrigel plug assays. Physiologically relevant concentrations of MIC-1 and not abnormally high levels were used in these models, demonstrating that MIC-1 could double directional blood vessel formation thereby confirming that it could play a role in angiogenesis. Collectively, these observations led to the conclusion that the mechanistic basis for tumor reduction after targeting MIC-1 was retardation in vascular development. However, it is possible that MIC-1 can also regulate other processes involved in tumor development or that other secreted factors could also cooperate in this process.

MIC- 1 is a member of the TGF- $\beta$ family, whose proteins perform a wide variety of complex and contradictory roles dependent on cancer type, tumor stage, interaction with tumor microenvironment, or genetic status of cyclin dependent kinase inhibitors such as p15 INK4b p2 $1^{\text {WAF } 1 / C I P 1}$, or Smads of the tumor cell. ${ }^{1,7}$ MIC-1 promotes tumor development under one circumstance and prevents it under another, making its function dependent on a particular tumor type. ${ }^{7,33}$ Although this is the first report indicating a role for MIC-1 in melanoma angiogenesis, it has also been documented to aid cancer development by upregulating transcription factors playing key roles in tumorigenesis such as nuclear factor- $\kappa \mathrm{B}$, early growth response factor-1, and microphthalmia-associated transcription factor in gastric cancer and melanomas. ${ }^{7,22,34}$ Increased MIC-1 expression also aids tumor development by activating epidermal growth factor receptor 2 tyrosine kinase in human breast and gastric cancer cells, which induced hypoxia inducible factor- $1 \alpha$ through PI3 and MAP kinase pathways. ${ }^{35} \mathrm{MIC}-1$ can increase expression of urokinase type plasminogen activator and the urokinase type plasminogen activator receptor as well as decreasing RhoE and catenin $\delta 1$ gene expression to reduce cell adhesion, thereby regulating cell migration through autocrine signaling. ${ }^{34,36}$ Additionally, MIC-1 can be inhibitory to tumor development as observed when p53 up-regulates MIC-1 expression to inhibit tumor growth by inducing cell cycle arrest and apoptosis. ${ }^{7,37-40}$ MIC-1 overexpression has also been found to increase

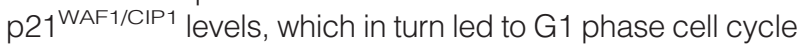
arrest. ${ }^{37}$ Whether MIC-1 regulates other important process in addition to angiogenesis in melanomas remains to be determined.

Constitutive activation of the MAP kinase pathway by $B$-Raf mutation is important for melanoma development leading to regulation of tumor cellular proliferation, apoptosis, vascular development, and metastasis. ${ }^{16,17,25}$ However, downstream genes regulating each of these essential tumorigenic processes remain to be fully identified. ${ }^{41-43}$ This report identifies MIC-1 as being one of these downstream proteins since decreased ${ }^{{ }^{6}{ }^{\circ}}{ }^{\circ} \mathrm{B}$-Raf expression reduced MIC-1 levels in and secretion from melanoma cells and ectopic expression of ${ }^{\mathrm{V} 600 \mathrm{E}} \mathrm{B}$-Raf in melanoma cells lacking this mutant protein increased MIC-1 secretion. The exact mechanism by which ${ }^{{ }^{6}}{ }^{\circ} E_{B}-$ Raf up-regulates MIC-1 expression remains to be fully elucidated but is likely to involve activation of transcription factors such as microphthalmia-associated transcription factor ${ }^{44,45}$ or nuclear factor- $\kappa \mathrm{B},{ }^{18,46}$ which play key roles in melanocyte differentiation as well as melanoma survival and proliferation. ${ }^{18,22,44,45}$ The MIC-1 promoter contains binding sites for these transcriptional regulators that could enhance its expression. ${ }^{22}$

VEGF is another angiogenic factor regulated by ${ }^{V 600 E} B$-Raf signaling in melanomas ${ }^{16} ; 2.5$ to $5.0 \mathrm{ng} / \mathrm{ml}$ MIC-1 and $200 \mathrm{pg} / \mathrm{ml}$ VEGF stimulation alone or in combination in this report increased blood vessel formation compared with controls. Other authors have shown that $100 \mathrm{ng} / \mathrm{ml}$ MIC-1 inhibits angiogenesis when co-stimulated with $100 \mathrm{ng} / \mathrm{ml}$ VEGF in the matrigel plug assay. ${ }^{47}$ This discrepancy is likely due to use of concentrations higher than the normal physiological range seen in melanomas $(0.5$ to $3.4 \mathrm{ng} / \mathrm{ml})$ and other cancers such as pancreatic cancer $(2.0$ to $2.5 \mathrm{ng} / \mathrm{ml}){ }^{11}$ It is well documented that proteins can be stimulatory at one concentration and inhibitory at a higher one as seen with the angiogenic properties of Hepatocyte Growth Factor (HGF). ${ }^{48}$ This possibility is further supported in this report by observation that concentrations higher than $10 \mathrm{ng} / \mathrm{ml}$ of MIC-1 led to a plateau effect in blood vessel formation in the chick chorioallantoic membrane vessel stimulation 
assay; $3.2 \mathrm{ng} / \mathrm{ml}$ was the highest concentration measured in serum from melanoma patients, suggesting higher amounts might not be more effective. Furthermore, 2.5 to $5.0 \mathrm{ng} / \mathrm{ml} \mathrm{MIC-1}$ and $200 \mathrm{pg} / \mathrm{ml}$ VEGF maximized vessels development in the matrigel plug assay again supporting this possibility.

In conclusion, ${ }^{6}{ }^{600} \mathrm{~B}-$ Raf signaling is one pathway regulating $\mathrm{MIC}-1$ expression, leading to secretion that stimulates angiogenesis and development of a vascular network enabling an increase in tumor size. Without MIC-1, melanoma tumor development can be stunted due to lack of vascular development, which in turn decreases cell proliferation and triggers apoptosis. Thus, MIC-1 is a useful prognostic marker, a regulator of angiogenesis, and a potentially important therapeutic target for melanoma.

\section{Acknowledgments}

We thank Hy-Line North America for generously providing fertilized chicken eggs for these studies. SubbaRao V. Madhunapantula and Angela Nguyen are thanked for their technical support.

\section{References}

1. Massague J: TGFbeta in cancer. Cell 2008, 134:215-230

2. Leivonen SK, Kahari VM: Transforming growth factor-beta signaling in cancer invasion and metastasis. Int J Cancer 2007, 121:2119-2124

3. Bootcov MR, Bauskin AR, Valenzuela SM, Moore AG, Bansal M, He XY, Zhang HP, Donnellan M, Mahler S, Pryor K, Walsh BJ, Nicholson RC, Fairlie WD, Por SB, Robbins JM, Breit SN: MIC-1, a novel macrophage inhibitory cytokine, is a divergent member of the TGF-beta superfamily. Proc Natl Acad Sci USA 1997, 94:11514-11519

4. Fairlie WD, Moore AG, Bauskin AR, Russell PK, Zhang HP, Breit SN: MIC-1 is a novel TGF-beta superfamily cytokine associated with macrophage activation. J Leukoc Biol 1999, 65:2-5

5. Hsiao EC, Koniaris LG, Zimmers-Koniaris T, Sebald SM, Huynh TV, Lee SJ: Characterization of growth-differentiation factor 15, a transforming growth factor beta superfamily member induced following liver injury. Mol Cell Biol 2000, 20:3742-3751

6. Karan D, Holzbeierlein J, Thrasher JB: Macrophage inhibitory cytokine-1: possible bridge molecule of inflammation and prostate cancer. Cancer Res 2009, 69:2-5

7. Bauskin AR, Brown DA, Kuffner T, Johnen H, Luo XW, Hunter M, Breit SN: Role of macrophage inhibitory cytokine-1 in tumorigenesis and diagnosis of cancer. Cancer Res 2006, 66:4983-4986

8. Welsh JB, Sapinoso LM, Kern SG, Brown DA, Liu T, Bauskin AR, Ward RL, Hawkins NJ, Quinn DI, Russell PJ, Sutherland RL, Breit SN, Moskaluk CA, Frierson HF Jr, Hampton GM: Large-scale delineation of secreted protein biomarkers overexpressed in cancer tissue and serum. Proc Natl Acad Sci USA 2003, 100:3410-3415

9. Brown DA, Ward RL, Buckhaults P, Liu T, Romans KE, Hawkins NJ, Bauskin AR, Kinzler KW, Vogelstein B, Breit SN: MIC-1 serum level and genotype: associations with progress and prognosis of colorectal carcinoma. Clin Cancer Res 2003, 9:2642-2650

10. Buckhaults P, Rago C, St Croix B, Romans KE, Saha S, Zhang L, Vogelstein B, Kinzler KW: Secreted and cell surface genes expressed in benign and malignant colorectal tumors. Cancer Res 2001, 61:6996-7001

11. Koopmann J, Buckhaults P, Brown DA, Zahurak ML, Sato N, Fukushima N, Sokoll LJ, Chan DW, Yeo CJ, Hruban RH, Breit SN, Kinzler KW, Vogelstein B, Goggins M: Serum macrophage inhibitory cytokine 1 as a marker of pancreatic and other periampullary cancers. Clin Cancer Res 2004, 10:2386-2392

12. Koopmann J, Rosenzweig CN, Zhang Z, Canto MI, Brown DA, Hunter
M, Yeo C, Chan DW, Breit SN, Goggins M: Serum markers in patients with resectable pancreatic adenocarcinoma: macrophage inhibitory cytokine 1 versus CA19-9. Clin Cancer Res 2006, 12:442-446

13. Welsh JB, Sapinoso LM, Su AI, Kern SG, Wang-Rodriguez J, Moskaluk CA, Frierson HF Jr, Hampton GM: Analysis of gene expression identifies candidate markers and pharmacological targets in prostate cancer. Cancer Res 2001, 61:5974-5978

14. Pollock PM, Harper UL, Hansen KS, Yudt LM, Stark M, Robbins CM, Moses TY, Hostetter G, Wagner U, Kakareka J, Salem G, Pohida T, Heenan P, Duray P, Kallioniemi O, Hayward NK, Trent JM, Meltzer PS: High frequency of BRAF mutations in nevi. Nat Genet 2003, 33:19-20

15. Pollock PM, Meltzer PS: A genome-based strategy uncovers frequent BRAF mutations in melanoma. Cancer Cell 2002, 2:5-7

16. Sharma A, Trivedi NR, Zimmerman MA, Tuveson DA, Smith CD, Robertson GP: Mutant V599EB-Raf regulates growth and vascular development of malignant melanoma tumors. Cancer Res 2005, 65:2412-2421

17. Sharma A, Tran MA, Liang S, Sharma AK, Amin S, Smith CD, Dong C, Robertson GP: Targeting mitogen-activated protein kinase/extracellular signal-regulated kinase kinase in the mutant (V600E) B-Raf signaling cascade effectively inhibits melanoma lung metastases. Cancer Res 2006, 66:8200-8209

18. Liang S, Sharma A, Peng HH, Robertson G, Dong C: Targeting mutant (V600E) B-Raf in melanoma interrupts immunoediting of leukocyte functions and melanoma extravasation. Cancer Res 2007, 67:5814-5820

19. Rotolo S, Diotti R, Gordon RE, Qiao RF, Yao Z, Phelps RG, Dong J: Effects on proliferation and melanogenesis by inhibition of mutant BRAF and expression of wild-type INK4A in melanoma cells. Int J Cancer 2005, 115:164-169

20. Riker Al, Enkemann SA, Fodstad O, Liu S, Ren S, Morris C, Xi Y, Howell P, Metge B, Samant RS, Shevde LA, Li W, Eschrich S, Daud A, Ju J, Matta J: The gene expression profiles of primary and metastatic melanoma yields a transition point of tumor progression and metastasis. BMC Med Genomics 2008, 1:13

21. Talantov D, Mazumder A, Yu JX, Briggs T, Jiang Y, Backus J, Atkins $D$, Wang Y: Novel genes associated with malignant melanoma but not benign melanocytic lesions. Clin Cancer Res 2005, 11:7234-7242

22. Boyle GM, Pedley J, Martyn AC, Banducci KJ, Strutton GM, Brown DA, Breit SN, Parsons PG: Macrophage inhibitory cytokine-1 is overexpressed in malignant melanoma and is associated with tumorigenicity. J Invest Dermatol 2009, 129:383-391

23. Stahl JM, Sharma A, Cheung M, Zimmerman M, Cheng JQ, Bosenberg MW, Kester M, Sandirasegarane L, Robertson GP: Deregulated Akt3 activity promotes development of malignant melanoma. Cancer Res 2004, 64:7002-7010

24. Madhunapantula SV, Sharma A, Robertson GP: PRAS40 deregulates apoptosis in malignant melanoma. Cancer Res 2007, 67:3626-3636

25. Cheung M, Sharma A, Madhunapantula SV, Robertson GP: Akt3 and mutant V600E B-Raf cooperate to promote early melanoma development. Cancer Res 2008, 68:3429-3439

26. Stahl JM, Cheung M, Sharma A, Trivedi NR, Shanmugam S, Robertson GP: Loss of PTEN promotes tumor development in malignant melanoma. Cancer Res 2003, 63:2881-2890

27. Rasband W: ImageJ. Edited by Bethesda, MD, US National Institutes of Health, 1997-2009

28. Tran MA, Gowda R, Sharma A, Park EJ, Adair J, Kester M, Smith NB, Robertson GP: Targeting V600EB-Raf and Akt3 using nanoliposomalsmall interfering RNA inhibits cutaneous melanocytic lesion development. Cancer Res 2008, 68:7638-7649

29. Murray JC (Ed): Angiogenesis protocols. Humana Press, Totowa, NJ 2001, ix, pp 267

30. Harborth J, Elbashir SM, Vandenburgh K, Manninga H, Scaringe SA Weber K, Tuschl T: Sequence, chemical, and structural variation of small interfering RNAs and short hairpin RNAs and the effect on mammalian gene silencing. Antisense Nucleic Acid Drug Dev 2003, 13:83-105

31. Witz IP: Tumor-microenvironment interactions: dangerous liaisons. Adv Cancer Res 2008, 100:203-229

32. Mueller MM, Fusenig NE: Friends or foes: bipolar effects of the tumour stroma in cancer. Nat Rev Cancer 2004, 4:839-849

33. Ago T, Sadoshima J: GDF15, a cardioprotective TGF-beta superfamily protein. Circ Res 2006, 98:294-297

34. Lee DH, Yang Y, Lee SJ, Kim KY, Koo TH, Shin SM, Song KS, Lee YH, 
Kim YJ, Lee JJ, Choi I, Lee JH: Macrophage inhibitory cytokine-1 induces the invasiveness of gastric cancer cells by up-regulating the urokinase-type plasminogen activator system. Cancer Res 2003 63:4648-4655

35. Kim KK, Lee JJ, Yang Y, You KH, Lee JH: Macrophage inhibitory cytokine-1 activates AKT and ERK-1/2 via the transactivation of ErbB2 in human breast and gastric cancer cells. Carcinogenesis 2008, 29:704-712

36. Liu T, Bauskin AR, Zaunders J, Brown DA, Pankhurst S, Russell PJ, Breit SN: Macrophage inhibitory cytokine 1 reduces cell adhesion and induces apoptosis in prostate cancer cells. Cancer Res 2003 63:5034-5040

37. Li PX, Wong J, Ayed A, Ngo D, Brade AM, Arrowsmith C, Austin RC, Klamut HJ: Placental transforming growth factor-beta is a downstream mediator of the growth arrest and apoptotic response of tumor cells to DNA damage and p53 overexpression. J Biol Chem 2000, 275:20127-20135

38. Tan M, Wang Y, Guan K, Sun Y: PTGF-beta, a type beta transforming growth factor (TGF-beta) superfamily member, is a p53 target gene that inhibits tumor cell growth via TGF-beta signaling pathway. Proc Natl Acad Sci USA 2000, 97:109-114

39. Wong J, Li PX, Klamut HJ: A novel p53 transcriptional repressor element (p53TRE) and the asymmetrical contribution of two p53 binding sites modulate the response of the placental transforming growth factor-beta promoter to p53. J Biol Chem 2002, 277: 26699-26707

40. Yang H, Filipovic Z, Brown D, Breit SN, Vassilev LT: Macrophage inhibitory cytokine-1: a novel biomarker for p53 pathway activation. Mol Cancer Ther 2003, 2:1023-1029
41. Gray-Schopfer V, Wellbrock C, Marais R: Melanoma biology and new targeted therapy. Nature 2007, 445:851-857

42. Hocker TL, Singh MK, Tsao H: Melanoma genetics and therapeutic approaches in the 21st century: moving from the benchside to the bedside. J Invest Dermatol 2008, 128:2575-2595

43. Madhunapantula SV, Robertson GP: Is B-Raf a good therapeutic target for melanoma and other malignancies? Cancer Res 2008, 68:5-8

44. Goding CR: Mitf from neural crest to melanoma: signal transduction and transcription in the melanocyte lineage. Genes Dev 2000, 14:1712-1728

45. Levy C, Khaled M, Fisher DE: MITF: master regulator of melanocyte development and melanoma oncogene. Trends Mol Med 2006 12:406-414

46. Dhawan P, Richmond A: A novel NF-kappa B-inducing kinase-MAPK signaling pathway up-regulates NF-kappa B activity in melanoma cells. J Biol Chem 2002, 277:7920-7928

47. Ferrari N, Pfeffer U, Dell'Eva R, Ambrosini C, Noonan DM, Albini A: The transforming growth factor-beta family members bone morphogenetic protein-2 and macrophage inhibitory cytokine- 1 as mediators of the antiangiogenic activity of $\mathrm{N}$-(4-hydroxyphenyl)retinamide. Clin Cancer Res 2005, 11:4610-4619

48. Uruno A, Sugawara A, Kudo M, Satoh F, Saito A, Ito S: Stimulatory effects of low-dose 3-hydroxy-3-methylglutaryl coenzyme a reductase inhibitor fluvastatin on hepatocyte growth factor-induced angiogenesis: involvement of p38 mitogen-activated protein kinase. Hypertens Res 2008 31:2085-2096 